\title{
Relationship between fractional pancreatic beta cell area and fasting plasma glucose concentration in monkeys
}

\author{
Y. Saisho • A. E. Butler • E. Manesso • R. Galasso • \\ L. Zhang • T. Gurlo • G. M. Toffolo $\cdot$ C. Cobelli • \\ K. Kavanagh • J. D. Wagner • P. C. Butler
}

Received: 9 July 2009 /Accepted: 27 August 2009/Published online: 22 October 2009

(C) Springer-Verlag 2009

\begin{abstract}
Aims/hypothesis We sought to establish the relationship between fasting plasma glucose concentrations and pancreatic fractional beta cell area in adult cynomolgus monkeys (Macaca fascicularis).

Methods Fasting plasma glucose and pancreatic fractional beta cell area were measured in 18 control and 17 streptozotocin-treated adult primates $(17.0 \pm 1.2$ vs $15.4 \pm$ 1.2 years old).

Results Fasting plasma glucose was increased $(12.0 \pm 2.0$ vs $3.4 \pm 0.1 \mathrm{mmol} / 1, p<0.01)$ and fractional beta cell area was decreased $(0.62 \pm 0.13 \%$ vs $2.49 \pm 0.35 \%, p<0.01)$ in streptozotocin-treated monkeys. The relationship between fasting plasma glucose and pancreatic fractional beta cell area was described by a wide range of beta cell areas in controls. In streptozotocin-treated monkeys there was an inflection of fasting blood glucose at $\sim 50 \%$ of the mean beta cell area in controls with a steep increase in blood glucose for each further decrement in beta cell area.
\end{abstract}

\footnotetext{
Y. Saisho • A. E. Butler • E. Manesso • R. Galasso • T. Gurlo

P. C. Butler $(\bowtie)$

Larry Hillblom Islet Research Center,

UCLA David Geffen School of Medicine,

900 Weyburn Place \#A,

Los Angeles, CA 90024-2852, USA

e-mail: pbutler@mednet.ucla.edu

E. Manesso - G. M. Toffolo • C. Cobelli

Department of Information Engineering, University of Padova,

Padua, Italy

L. Zhang $\cdot$ K. Kavanagh $\cdot$ J. D. Wagner

Department of Pathology,

Wake Forest University School of Medicine,

Winston-Salem, NC, USA
}

Conclusions/interpretation In adult non-human primates a decrement in fractional beta cell area of $\sim 50 \%$ or more leads to loss of glycaemic control.

Keywords Beta cell mass - Cynomolgus monkey Streptozotocin - Type 1 diabetes - Type 2 diabetes

\author{
Abbreviations \\ FPG Fasting plasma glucose \\ STZ Streptozotocin
}

\section{Introduction}

In health, the blood glucose concentration is regulated by insulin secreted by pancreatic beta cells. Diabetes arises when insufficient insulin is secreted to maintain glycaemic control. In type 1 and type 2 diabetes this is at least in part due to a deficit in beta cell mass [1-3]. There is inconsistency in the published literature as to what constitutes sufficient beta cell mass to sustain glycaemic control. The surgical literature has suggested as much as an $80 \%$ pancreatic resection can be tolerated without diabetes $[4,5]$. However, more comprehensive metabolic studies of humans and dogs after a partial pancreatectomy have suggested that $\sim 50 \%$ pancreatectomy results in impaired fasting glucose and glucose intolerance in the short term [6] and diabetes in some individuals over the next few years $[7,8]$.

The latter data are consistent with cross-sectional studies of the relationship between fasting blood glucose concentration and pancreatic fractional area in humans [3]. In obese individuals, this relationship is curvilinear, with an inflection of blood glucose with a deficit of $\sim 50 \%$ or more 
beta cells compared with controls. On the other hand, in another study of dogs it was suggested that insulin secretion was minimally effected with an $\sim 50 \%$ pancreatic resection [9].

Here we report the relationship between fasting plasma glucose (FPG) and fractional pancreatic beta cell area in adult cynomolgus monkeys (Macaca fascicularis).

\section{Methods}

Animals A total of 35 male cynomolgus monkeys (Macaca fascicularis, age: $16.2 \pm 0.9$ years, range 5 to 27 years; body weight: $5.8 \pm 0.3 \mathrm{~kg}$, range 3.4 to $9.8 \mathrm{~kg}$ ) were studied. Monkeys were originally imported from Institut Pertanian (Bogar, Indonesia) and were pair-housed at the Comparative Medicine Clinical Research Center at Wake Forest University School of Medicine, Winston-Salem, NC, USA. Among them, 18 monkeys (nine control and nine streptozotocin [STZ]-treated monkeys) had been included in a previous study reported elsewhere [10]. Monkeys were randomly assigned to either the control $(n=18)$ or the STZ $(n=17)$ group. Control and STZ groups were matched for age (17.0 \pm 1.2 vs $15.4 \pm 1.2$ years, $p=0.3)$ and body weight $(6.1 \pm 0.4$ vs $5.6 \pm 0.3 \mathrm{~kg}, p=0.3)$. All procedures involving animals were conducted in compliance with state and federal laws, standards of the US Department of Health and Human Services, and guidelines established by the Wake Forest University Institutional Animal Care and Use Committee.

Induction of diabetes To induce diabetes, freshly prepared STZ (Zanosar; SICOR Pharmaceuticals, Irvine, CA, USA) was given intravenously in a single bolus $(30 \mathrm{mg} / \mathrm{kg}$ ) to monkeys in the STZ group. To monitor the effect of STZ, the fasting blood glucose concentration was measured on alternate days for a week, (Accu-Check Glucose Monitor; Boehringer Mannheim, Indianapolis, IN, USA). Of the 17 monkeys in the STZ group, six required a second STZ injection 1 week after the first and three monkeys required a third STZ injection 1 week after the second to induce diabetes. The criterion for diabetes was a fasting blood glucose $>8 \mathrm{mmol} / 148 \mathrm{~h}$ post STZ injection. To avoid ketosis in hyperglycaemic monkeys, insulin therapy (Novolin 70/30; Novo Nordisk USA, Princeton, NJ, USA) was started at a dosage of $0.4 \mathrm{U} / \mathrm{kg}$ twice daily and then the dose was gradually increased to a target fasting blood glucose concentration of 8 to $14 \mathrm{mmol} / \mathrm{l}$.

Fasting blood samples were collected under ketamine sedation 4 weeks (nine control and nine STZ monkeys) or 14 weeks (nine control and eight STZ monkeys) after the STZ (or saline) injection. To avoid the effect of exogenous insulin, monkeys were treated with the same dose of regular insulin (Novolin R; Novo Nordisk USA) instead of Novolin $70 / 30$ on the evening prior to blood sampling. Plasma glucose concentration was determined by the glucose oxidase method by using a Glucose Analyzer 2 (Beckman Instruments, Brea, CA, USA).

Tissue collection After collection of the blood samples (i.e. 4 or 14 weeks after the STZ [or saline] treatment), the animals were killed by overdose with intravenous pentobarbital, and the pancreases were harvested intact, immediately weighed, cut into 3-4 mm sections and fixed in ice-cold neutralbuffered $10 \%$ (vol./vol.) formalin for $24 \mathrm{~h}$. The pancreases were then transferred into $70 \%$ (vol./vol.) alcohol for another $24 \mathrm{~h}$ at $4^{\circ} \mathrm{C}$ prior to processing and embedding in paraffin for the subsequent procedure.

Morphometric analysis For immunohistochemistry, $4 \mu \mathrm{m}$ sections of pancreas containing a minimum of 100 islets were stained with guinea pig anti-insulin antibody, 1:100 (Zymed Laboratories, San Francisco, CA, USA) and haematoxylin. Then the entire pancreatic section stained for insulin was imaged at $\times 40$ magnification ( $\times 4$ objective). The ratio of the beta cell area/total pancreas parenchymal area was digitally quantified using Image Pro Plus software (Media Cybernetics, Silver Springs, MD, USA) as previously described [2].

Statistical analysis Data are presented as mean \pm SEM. The Student's $t$ test was used for comparisons. The relation between the fasting plasma glucose $(y$ in $\mathrm{mmol} / \mathrm{l})$ and the beta cell area $(x$ in \%) was described with the model

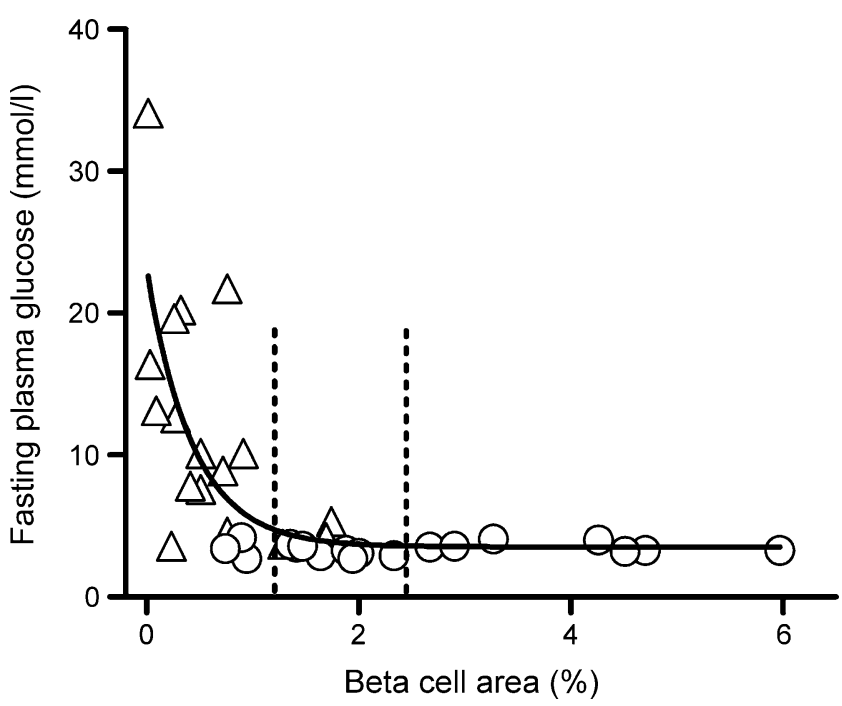

Fig. 1 Curvilinear relationship between the percentage of pancreas occupied by beta cells and fasting plasma glucose in cynomolgus monkeys. Circles, control monkeys; triangles, STZ-treated monkeys. The solid line is derived from non-linear regression analysis $\left(r^{2}=0.59\right.$; $p<0.0001)$. The dashed vertical lines indicate the mean fractional pancreatic beta cell area in the control group $(2.5 \%$, right $)$ and $\sim 50 \%$ of that value $(1.3 \%$, left $)$ 
proposed by Ritzel et al. [3], describing a mono-exponential decay plus plateau:

$y=$ plateau $+\operatorname{span} \times \mathrm{e}^{-\mathrm{k} \times x}$

where plateau $(\mathrm{mmol} / \mathrm{l})$ was the FPG value related to elevated beta cell areas, span $(\mathrm{mmol} / \mathrm{l})$ was the increase above plateau corresponding to a beta cell area equal to zero, and $\mathrm{k}\left(\%^{-1}\right)$ was the constant rate of the monoexponential function.

Model variables (i.e. plateau, span and k) were estimated, together with a measure of their precision (coefficient of variation), by non-linear least squares [11] using SAAM II software [12].

\section{Results}

As expected, the fasting plasma glucose concentrations measured shortly before death and necropsy were higher in STZ-treated diabetic monkeys compared with control monkeys $(12.0 \pm 2.0$ vs $3.4 \pm 0.1 \mathrm{mmol} / 1, p<0.01)$. Also, the pancreatic fractional beta cell area was decreased in STZ-treated diabetic monkeys compared with control monkeys $(0.62 \pm 0.13 \%$ vs $2.49 \pm 0.35 \%, p<0.01)$.

The relationship between the fasting plasma glucose concentration and the pancreatic fractional insulin area was well described by the mono-exponential model relationship in equation 1 (Fig. 1). The model variables were estimated with good precision: plateau $=3.5 \pm 1.3 \mathrm{mmol} / 1(\mathrm{CV} 37 \%)$, span $=19.4 \pm 3.1 \mathrm{mmol} / 1 \quad(\mathrm{CV} 16 \%), \mathrm{k}=2.3 \pm 0.7 \%^{-1} \quad(\mathrm{CV}$ $33 \%)$. There was a wide range of fractional beta cell areas in control monkeys. Blood glucose concentrations increased steeply once the pancreatic fractional beta cell area decreased to $50 \%$ or less that of the mean of that in control monkeys.

\section{Discussion}

We report that the relationship between the pancreatic fractional beta cell area and the fasting plasma glucose concentration in cynomolgus monkeys is reminiscent of that in humans with and without type 2 diabetes [3]. The relationship is also comparable with that observed previously in a porcine [13] and rat model of diabetes [14] compared with their respective non-diabetic controls.

In each of these models there is a wide range of fractional beta cell areas in the non-diabetic controls [3, $13,14]$. It is conceivable that this is due to variation in pancreas volume [15]. However, a wide range of beta cell masses in non-diabetic humans has also been reported [16].
Alternatively, the wide range in fractional beta call areas in non-diabetic individuals represents adaptation to insulin sensitivity. However, this seems unlikely, at least in humans, as in morbidly obese humans the adaptive increase in beta cell mass is only $50 \%$ compared with that in lean individuals [2,16-18]. Another possible explanation is that maternal nutrition [19], placental function and both nutrition and genetic regulation during postnatal expansion of beta cell mass may define the adult beta cell mass [20].

The relationship between fractional beta cell area and the fasting blood glucose concentration in adult STZ-treated monkeys reported here is also comparable with that in models of type 2 diabetes in adult rats [14] and pigs [13]. In these models, once the fractional beta cell area is decreased by approximately $50 \%$ or more of that in non-diabetic individuals, glycaemic control is lost. After a loss of $50 \%$ of beta cells in each of these models, there is steep rise in fasting blood glucose concentration with each further decrement in beta cell area. This curvilinear relationship reported in adult rodents, pigs and now non-human primates reproduces that previously observed in humans [3]. Moreover, a similar relationship has recently been reported in humans with pancreatitis [21].

The mechanisms responsible for the loss of regulation of glycaemic control after a decrease in pancreatic beta cell area of $50 \%$ or more is unknown. One plausible explanation is that with declining beta cell mass the immediately secretable insulin pool [22] is depleted leading to an impaired insulin pulse mass, as previously documented after $50 \%$ pancreatectomy [6]. Since the pattern of insulin delivery to the liver influences insulin sensitivity [23, 24], we postulate that once the immediately secretable insulin pool is depleted, impaired pulsatile insulin leads to insulin resistance that further confounds the defect in insulin secretion. Once hyperglycaemia develops, the additional confounding adverse effects of hyperglycaemia on beta cell function and insulin sensitivity presumably contribute to the further declining glycaemic control.

In conclusion, in adult non-human primates, a decline of approximately $50 \%$ or more in pancreatic beta cells leads to loss of glycaemic control with a relationship comparable with that in adult humans. The cynomolgus monkey treated with sufficient STZ to induce this deficit in beta cells is therefore a useful model for type 2 diabetes.

Acknowledgement This study was supported by funding from the NIH (DK059579, DK077967), the Juvenile Diabetes Research Foundation (7-2005-1152), the Larry L. Hillblom Foundation and the Manpei Suzuki Diabetes Foundation. We are grateful to our colleagues in the Larry Hillblom Islet Research Center for their excellent suggestions.

Duality of interest The authors declare that there is no duality of interest associated with this manuscript. 


\section{References}

1. Butler AE, Galasso R, Meier JJ, Basu R, Rizza RA, Butler PC (2007) Modestly increased beta cell apoptosis but no increased beta cell replication in recent-onset type 1 diabetic patients who died of diabetic ketoacidosis. Diabetologia 50:2323-2331

2. Butler AE, Janson J, Bonner-Weir S, Ritzel R, Rizza RA, Butler PC (2003) Beta-cell deficit and increased beta-cell apoptosis in humans with type 2 diabetes. Diabetes 52:102-110

3. Ritzel RA, Butler AE, Rizza RA, Veldhuis JD, Butler PC (2006) Relationship between beta-cell mass and fasting blood glucose concentration in humans. Diabetes Care 29:717-718

4. King J, Kazanjian K, Matsumoto J et al (2008) Distal pancreatectomy: incidence of postoperative diabetes. J Gastrointest Surg 12:1548-1553

5. Lillemoe KD, Kaushal S, Cameron JL, Sohn TA, Pitt HA, Yeo CJ (1999) Distal pancreatectomy: indications and outcomes in 235 patients. Ann Surg 229:693-698 discussion 698-700

6. Matveyenko AV, Veldhuis JD, Butler PC (2006) Mechanisms of impaired fasting glucose and glucose intolerance induced by an approximate $50 \%$ pancreatectomy. Diabetes 55:23472356

7. Robertson RP, Lanz KJ, Sutherland DE, Seaquist ER (2002) Relationship between diabetes and obesity 9 to 18 years after hemipancreatectomy and transplantation in donors and recipients. Transplantation 73:736-741

8. Kumar AF, Gruessner RW, Seaquist ER (2008) Risk of glucose intolerance and diabetes in hemipancreatectomized donors selected for normal preoperative glucose metabolism. Diabetes Care 31:1639-1643

9. Ward WK, Wallum BJ, Beard JC, Taborsky GJ Jr, Porte D Jr (1988) Reduction of glycemic potentiation. Sensitive indicator of beta-cell loss in partially pancreatectomized dogs. Diabetes 37:723-729

10. Wagner JD, Zhang L, Greaves KA, Shadoan MK, Schwenke DC (2000) Soy protein reduces the arterial low-density lipoprotein (LDL) concentration and delivery of LDL cholesterol to the arteries of diabetic and nondiabetic male cynomolgus monkeys. Metabolism 49:1188-1196

11. Carson ER, Cobelli C, Finkelstein L (1983) The mathematical modeling of metabolic and endocrine systems. Wiley, New York
12. Barrett PH, Bell BM, Cobelli C et al (1998) SAAM II: simulation, analysis, and modeling software for tracer and pharmacokinetic studies. Metabolism 47:484-492

13. Kjems LL, Kirby BM, Welsh EM et al (2001) Decrease in betacell mass leads to impaired pulsatile insulin secretion, reduced postprandial hepatic insulin clearance, and relative hyperglucagonemia in the minipig. Diabetes 50:2001-2012

14. Matveyenko AV, Butler PC (2006) Beta-cell deficit due to increased apoptosis in the human islet amyloid polypeptide transgenic (HIP) rat recapitulates the metabolic defects present in type 2 diabetes. Diabetes 55:2106-2114

15. Saisho Y, Butler AE, Meier JJ et al (2007) Pancreas volumes in humans from birth to age one hundred taking into account sex, obesity, and presence of type-2 diabetes. Clin Anat 20:933-942

16. Rahier J, Guiot Y, Goebbels RM, Sempoux C, Henquin JC (2008) Pancreatic beta-cell mass in European subjects with type 2 diabetes. Diabetes Obes Metab 10(Suppl 4):32-42

17. Meier JJ, Butler AE, Galasso R, Butler PC (2006) Hyperinsulinemic hypoglycemia after gastric bypass surgery is not accompanied by islet hyperplasia or increased beta-cell turnover. Diabetes Care 29:1554-1559

18. Saisho Y, Butler AE, Monchamp T et al (2007) Does beta cell mass adaptively increase in response to obesity in humans? Diabetes 56(Suppl 1):A48

19. Schwitzgebel VM, Somm E, Klee P (2009) Modeling intrauterine growth retardation in rodents: impact on pancreas development and glucose homeostasis. Mol Cell Endocrinol 304:78-83

20. Freathy RM, Bennett AJ, Ring SM et al (2009) Type 2 diabetes risk alleles are associated with reduced size at birth. Diabetes 58:1428-1433

21. Meier JJ, Menge BA, Breuer TG et al (2009) Functional assessment of pancreatic beta-cell area in humans. Diabetes 58:1595-1603

22. Daniel S, Noda M, Straub SG, Sharp GW (1999) Identification of the docked granule pool responsible for the first phase of glucosestimulated insulin secretion. Diabetes 48:1686-1690

23. Matveyenko AV, Butler PC (2008) Relationship between beta-cell mass and diabetes onset. Diabetes Obes Metab 10(Suppl 4):23-31

24. Paolisso G, Scheen AJ, Giugliano D et al (1991) Pulsatile insulin delivery has greater metabolic effects than continuous hormone administration in man: importance of pulse frequency. J Clin Endocrinol Metab 72:607-615 